Research Article

\title{
Application of Data Mining Technology in Field Verification of Project Cost
}

\author{
Yi Jiang \\ Henan Finance University, Zhengzhou 451464, China \\ Correspondence should be addressed to Yi Jiang; jiangyi@hafu.edu.cn \\ Received 19 October 2021; Revised 4 November 2021; Accepted 19 November 2021; Published 7 December 2021 \\ Academic Editor: Qiangyi Li \\ Copyright (c) $2021 \mathrm{Yi}$ Jiang. This is an open access article distributed under the Creative Commons Attribution License, which \\ permits unrestricted use, distribution, and reproduction in any medium, provided the original work is properly cited.

\begin{abstract}
The traditional budget quota pricing model seems incompatible with the continuous development of the market economy. Low degree of visualization, extensive resource management, difficulty in collecting construction data, lagging control work, and separation of cost control from project management have become the main problems of current construction project cost control. This paper combines data mining technology to improve the project cost on-site verification network system, build a project cost verification system that can be used for on-site verification, and build a cost information platform. Moreover, this paper makes full use of computer information technology and uses the local area network and network as the basis to transform the vertical transmission of cost information into horizontal, so as to ensure the effective communication and exchange of cost information. According to the analysis of the case study, it can be seen that the project cost field verification method based on data mining proposed in this paper is very effective, and the system proposed in this paper can be used in actual projects.
\end{abstract}

\section{Introduction}

In recent years, the competition in the construction market has become increasingly fierce, and the market competition mechanism is not perfect. Construction companies are vying for survival, lowering prices and making profits, winning bids and even bidding prices lower than the cost of the project, resulting in low economic benefits for enterprises [1]. Therefore, if an enterprise wants to create good benefits and achieve sustainable development, it is the only way to strengthen the cost management and control of its own projects. At present, the project cost management control of China's construction industry is still at a low-level, extensive, and experience-based stage. Moreover, most companies have imperfect cost control systems, weak cost management awareness, backward and unscientific cost control methods and methods, and lack of proper management efficiency. In addition, the organization and management of enterprises are loose, and there is a lack of effective mechanisms for coordination and cooperation between departments. At the same time, the implementation of the project cost management responsibility system is not clear, the assessment mechanism is formalized, and the incentive mechanism is not sound, which affect the growth of economic benefits of the enterprise. Therefore, in order to solve the development bottleneck, enhance the competitiveness of the company, expand the company's market share, and achieve sustainable development of the company, construction enterprises must strive to improve the level of cost control, promote the optimization of construction project cost control, enhance the profitability of construction projects, and improve corporate benefits [2].

The previous cost control model has obviously lags behind the development of the times and is not suitable for or even restricts the rapid development of enterprises. However, project cost control is a very important link in the project management process. As a key activity to be performed by the project team, the project cost control of different construction companies is different. On the basis of mastering the theory of cost control, exploring the cost control mode suitable for the enterprise itself through practice has important theoretical significance for the cost control and management of the entire construction enterprise [3]. 
Foreign countries have established a professional completed project cost case management agency to collect and sort out the cost cases and have achieved remarkable results in measuring the construction costs of other projects. At present, in the process of urbanization in China, real estate has been rapidly developed, and construction projects are blooming everywhere, which will inevitably produce a large number of completed project cost cases. However, the cost information of completed projects has not been collected and managed uniformly. When it is then used to guide the implementation of subsequent projects, this is undoubtedly a major waste of resources.

This article combines the actual needs of project cost verification to build a project cost verification system that can be used for on-site verification, which changes the disadvantages of traditional project cost verification and provides a reference for the efficiency improvement of subsequent project cost verification.

\section{Related Work}

The choice and application of cost control methods are directly related to cost control. The literature [4] introduced the project responsibility cost control method into the engineering project cost management, explained the reasons for choosing this method, and discussed the advantages and disadvantages of the project responsibility cost control method applied to the engineering project. The literature [5] analyzed the theoretical basis of the earned value method and applied it in practice in the project of Hunan International Convention and Exhibition Center. The literature [6] proposed a multifactor cost analysis model based on Analytic Hierarchy Process (AHP). This model uses cost factors as variables and government evaluation as the budget standard and finally obtains the cumulative distribution of the budget boundaries of construction projects. The literature [7] proposed to monitor the cost dynamically and in real time, strictly control the cost expenditure with the target cost, and carry out cost control in accordance with the timely update schedule plan. The literature [8] compared the accuracy of support vector machine (SVM), neural network method (NN), and regression analysis method (RA) in predicting the cost of campus construction projects. The results show that the NN model has the highest accuracy. The literature [9] comprehensively used the basic deduction method and case method to develop a construction cost estimation model for ecological river construction projects. Literature [10] proposed a construction project evaluation method based on the four dimensions of cost, process, quality, and safety and gave a specific comprehensive score calculation method and pointed out the important position of cost in the selection of construction projects. The literature [11] studied the deviation analysis indicators in the earned value method and verified the application of the earned value method in the cost management of construction projects through case analysis.

The project cost and its quality, duration, and safety are mutually restricted and closely linked. In order to optimize the relationship between them, literature [12] based on the theory of multiattribute utility function and based on network technology constructed a comprehensive equilibrium optimization model of cost-quality-construction period and solved the model through genetic algorithm to find the optimal relationship between the three in mathematics and physics. Construction rework leads to an increase in unnecessary costs. Strict quality control can effectively reduce or even eliminate rework costs. Literature [13] uses a multistep linear regression method to explore the most important factors leading to rework costs and finally concludes that customer-initiated changes and design scope freezes. And the ineffective application of information technology is an important factor in causing rework. Literature [14] research results show that contractors believe that the greatest significance of implementing quality cost control is to improve the cost awareness and quality awareness of management and all employees. Staff quality, system issues, and corporate culture are the main factors hindering the implementation of quality cost control. Literature [15] explained the concept of project cost control and proposed the elements of project cost control, including project quality, project schedule and cost relationship, human resource management, and operation process management. Literature [16] mainly discusses the relationship and control of the factors such as cost, quality, construction period and safety of construction project management. The construction schedule directly affects the cost payment of construction projects. Literature [17] shows the relationship between time schedule and cost, and literature [18] verifies the applicability of the time cost model in Korea, especially for cost planning and cost control in the early stage of construction Influence. Literature [19] further explained and analyzed the impact of quality, cost, construction period, and safety on the cost of construction projects. In recent years, environmental changes have received more and more attention, and the environmental impact cost of construction projects has become an important item in construction costs. Literature [20] established an ICCSM system that integrates carbon dioxide emission cost and schedule control based on the earned value management theory and conducts related cost management by predicting, planning, controlling, and evaluating carbon dioxide emissions during the construction process.

\section{Analysis of Digital Network Resources of Project Cost}

The network structure of the cognitive network is complex and changeable, so it is more difficult to manage it. On the other hand, in future network implementations, wireless networks will be more unpredictable. Therefore, in order to shield the differences between these networks and facilitate unified management, the author made a detailed analysis process for the cognitive network engineering cost data, which is convenient for the efficient use of the engineering cost data.

In a topological network, the network is composed of points and lines. Corresponding to the physical communication network, the topological point corresponds to the 
node equipment in the network, and the topological line corresponds to various links in the network. Due to the difference and particularity of the terminal node and the network node, it is proposed separately for description. Similar to this, the network engineering cost data can be divided into terminal engineering cost data, network node engineering cost data, and link engineering cost data, as shown in Figure 1.

The representation of the decomposition process is listed, as shown in formula:

$$
R_{\mathrm{CN}}=\left\{R_{\text {Ter min } d}, R_{\text {Node }}, R_{\text {Link }}\right\} .
$$

The terminal engineering cost data $R_{T e r \text { min } d}$ is the sum of the capabilities of the terminal of the communication network that can support any mode change in the network communication. It may include terminal standards, protocols and software modules, basic hardware, energy, etc.

The nodes of the communication network are generally divided into access nodes and relay nodes according to their function differences in the network. Correspondingly, the network node project cost data $R_{\text {Node }}$ is also divided into access node project cost data and relay node project cost data.

$$
R_{\text {Node }}=\left\{R_{\text {Access-Node }}, R_{\text {Relay-Node }}\right\} .
$$

Similarly, the links in the communication network can be divided into two types, one is the access link and the other is the relay link. Therefore, the network link project cost data $R_{\text {Link }}$ is then divided into the access link project cost data and the relay link project cost data.

$$
R_{\text {Link }}=\left\{R_{\text {Access-Link }}, R_{\text {Relay-Link }}\right\} .
$$

Since the commonly discussed cognitive network is aimed at a wireless communication network using mobile terminals, and the access link from the mobile terminal to the network access point is a wireless link, the following equivalent definitions can be made:

$$
R_{\text {Access-Link }}=R_{\text {Spectrum }} \text {. }
$$

From the above analysis, it can be seen that the network engineering cost data of the cognitive network is a collection of multiple different engineering cost data parts, namely,

$$
R_{C N}=\left\{R_{\text {Ter mind }}, R_{\text {Access-Node }}, R_{\text {Relay-Node }}, R_{\text {Spectrum }}, R_{\text {Relay-Link }}\right\} .
$$

In this way, the first-layer physical functional decomposition process of the engineering cost data of the cognitive network is completed, and the engineering cost data are composed of engineering cost data elements. Specifically, the network project cost data are composed of terminal project cost data, access node project cost data, relay node project cost data, spectrum project cost data, and relay link project cost data. The structural relationship can be shown in Figure 2.

Based on the overall decomposition of project cost data into a collection of multiple project cost data elements, in order to better distinguish and describe the project cost data, the overall abstract concept component of the physical function entity of the project cost data element will be further studied to form the second level of decomposition.

The decomposition of the first layer of the network as a whole is based on the actual network structure, and the functional decomposition is carried out from the perspective of the overall set. The formed components are also physical parts with physical functions and practical meanings. However, for the project cost data elements discussed in the second layer, what it represents is only the common logical concept of multiple specific physical components, so the way of decomposition and analysis is different from that of the first layer.

Due to the description relationship between the feature parameters and the engineering cost data elements and the correlation characteristics between the feature parameters, the way that the feature parameters constitute the project cost data elements is different from the way that the project cost data elements are combined to form the overall project cost data. Since the various engineering cost data elements are independent of each other, and each has its own clear meaning, it can be represented by a set. However, the feature parameters need to be supported by mutual correlation and are no longer a purely collective relationship. In order to reflect the overall significance of the characteristic parameters, formula (6) is used to express the relationship between the project cost data elements and the characteristic parameters.

$$
R E\left(R_{\text {element-name }}\right)=\text { Struct }\{\text { APara, } \text { SPara }\} .
$$

Among them, the Struct $\{\cdot\}$ operator represents an overall structure constructed by several parameters. In addition to reflecting the meaning and composition of each parameter itself, it also needs to reflect the relationship between specific parameters. Using formula (6), each project cost data element formed by the first-level decomposition can be described by attribute parameters and state parameters.

According to the above two-level decomposition method description, it is possible to form attribute parameters and state parameters to describe each kind of project cost data element. After that, the project cost data elements are merged to form an analysis structure of the project cost data as a whole, as shown in Figure 3.

The database can complete the storage and analysis of the cognitive network engineering cost data, and designing a complete database can make the management of the cognitive network engineering cost data operable and specific. The design database is shown in Figure 4.

As can be seen from Figure 4, the database has the following functions:

(1) The database supports multiple interfaces, such as project cost data information interface, business request interface, and project cost data distribution interface. 

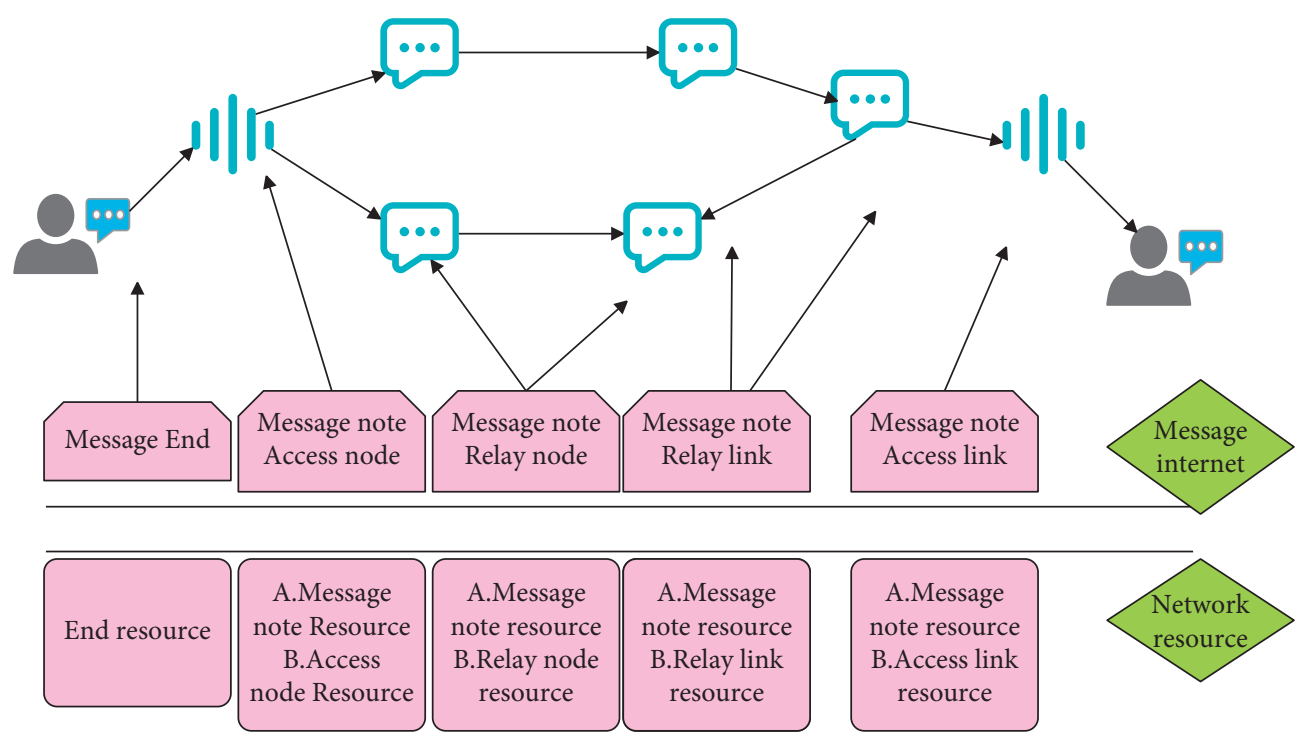

FIGURE 1: Schematic diagram of network composition and corresponding cognitive network project cost data decomposition.

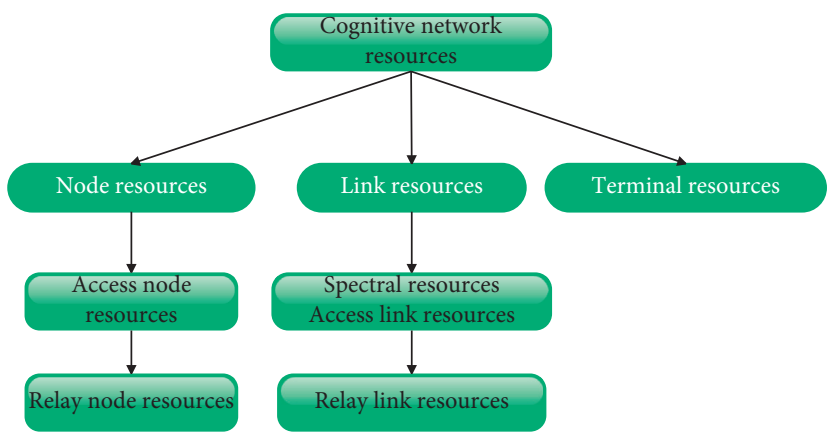

Resource elements

Figure 2: The first-level functional decomposition structure of network engineering cost data.
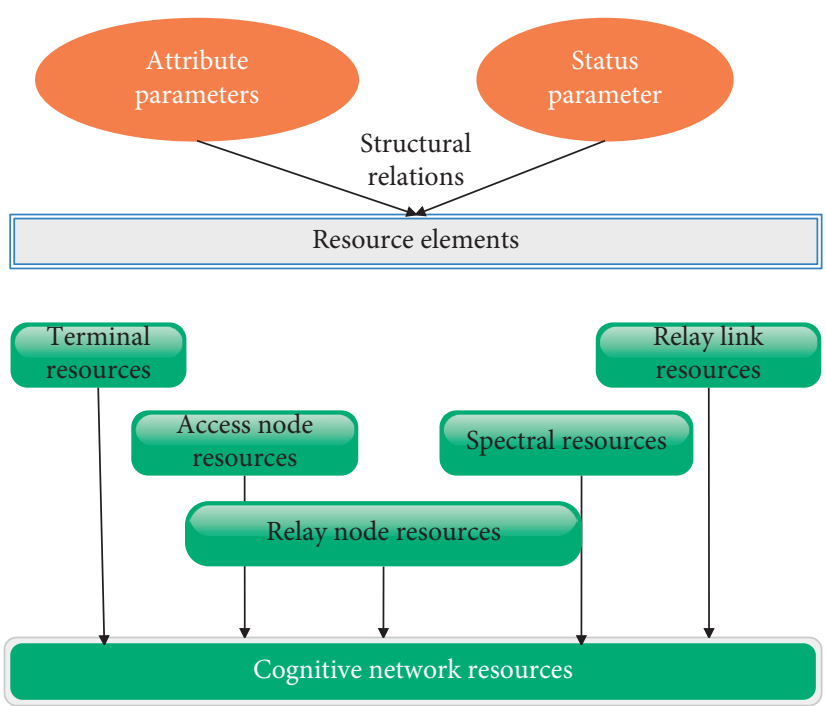

Set merge

FIGURE 3: The relationship and analysis structure of project cost data, project cost data elements, and characteristic parameters. 


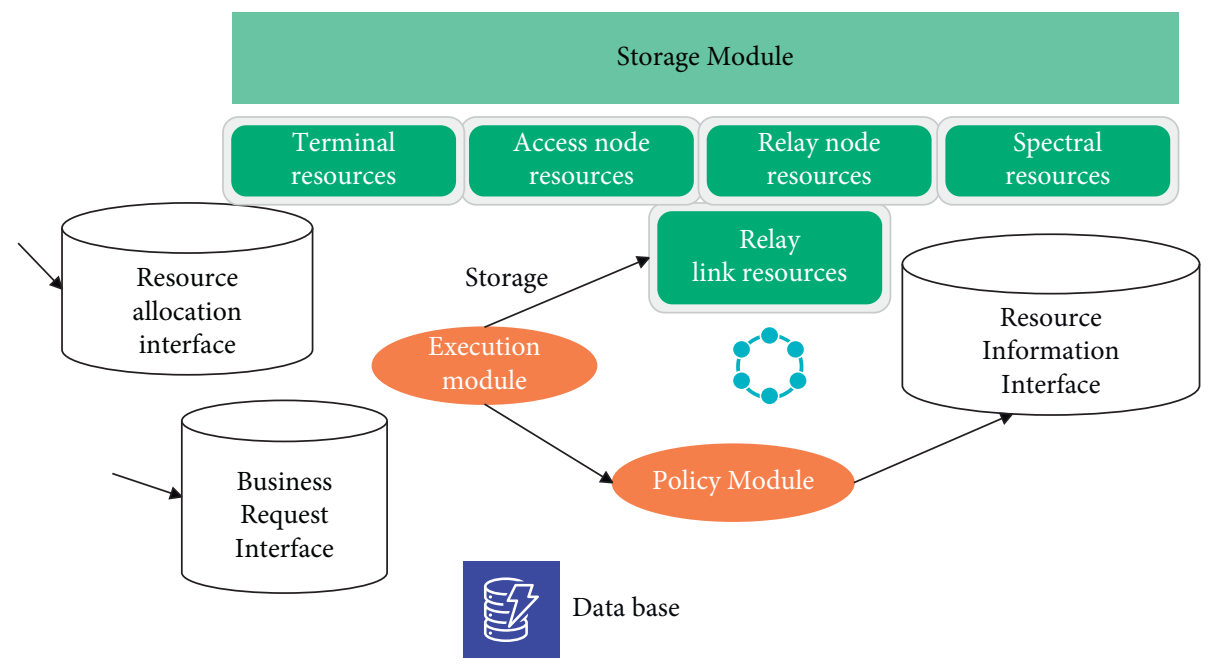

FIgURE 4: Schematic diagram of the database.

(2) The database can perform business analysis. If it is project cost data information, it can store it. If it is for business information, enter the strategy module.

(3) The database can summarize and analyze the project cost data information.

(4) For business requests, the database can enter the execution module and give specific feasible solutions.

The database management system designed in this paper can provide services for the storage, query, and analysis of project cost data information. The information content it stores and records can be obtained in the following two ways.

Obtain the project cost data information through the database interface and organize it to form a database storage format to store and record the project cost data information.

The database itself has a certain ability to derive data. It can obtain the complete information of the project cost data through certain calculations, supplements, or derivations through partial or partial information of the state of the project cost data. For the first method, a specific format has been developed for the project cost data information in Section 2 of the database interface design. As long as the unified interface is used, certain project cost data status information can be provided to the database. For the second method, we use a special case of spectrum engineering cost data to illustrate.

Spectrum engineering cost data elements are very important in cognitive network engineering cost data. Spectrum information is a complete manifestation of spectrum engineering cost data in terms of space, time, and frequency. Spectrum engineering cost data information can be obtained through sensing technology, but the information obtained through spectrum sensing is only the spectrum information of the location of the sensing monitoring point and cannot reach the description of the state of the spectrum engineering cost data for all spatial locations in the spectrum engineering cost data characterization. Based on the above reasons, the database is required to have the ability to obtain the status information of the spectrum engineering cost data for each location in the area through certain calculations and deductions based on the actual monitored spectrum engineering cost data information. Here, a calculation method is given to obtain complete project cost data status information.

The specific calculation process of this method is to use spectrum sensing technology to obtain the power of some specific monitoring points and use the information at this point to calculate the complete information of the interference source. Then, it uses the information of the interference source and the calculation formula to obtain the received power value at each point in the investigation area. In this way, there is a corresponding received power value for each spatial position in the area, and finally, the color temperature map of the investigated area is obtained by using the RGB value of the color.

In this method, how to obtain interference source information is a very important step. The interference source information mainly includes the following quantities: the number of interference sources, location, and transmit power. Here, it is mainly divided into the following three situations for analysis: (1) the location and number of interference sources are known, (2) only the number of interference sources is known, and (3) any information about interference sources is unknown.

The workflow of this method is shown in Figure 5 above. According to Figure 5, the specific analysis process is given:

Through spectrum sensing technology, we obtain the spectrum information of the location of the sensing monitoring point, that is, the received power value $T_{m}(f)$ of each monitoring point. The data information can be obtained through the SOCKET communication module, and the module definition is specifically introduced.

We do a specific analysis of the three scenarios and use the method in which scenario to meet which scenario. The following are the processing methods for three wireless scenarios: 
The location $\left(x_{i}, y_{i}\right)$ and number $L$ of the interference source are known, but the transmit power $p_{l}^{(f)}$ of the interference source on the frequency band under investigation is unknown. The received power formula is

$$
T_{m}(f)=\sum_{l=1}^{L} F\left(P_{l}^{(f)}, x_{l}, y_{l}, u_{m} . v_{m}, f\right) \text {. }
$$

Among them, $\left(u_{m} \cdot v_{m}\right)$ is the spatial position coordinates of the $m$ th monitoring point, and $F\left(P_{l}^{(f)}, x_{l}, y_{l}, u_{m} . v_{m}, f\right)$ represents the received power of the $I$ th interference source received by the $m$ th monitoring point on the investigated frequency band. If the selected propagation model is different, the calculation formula is also different. Here, we can choose to use the free space propagation model, then

$$
F\left(P_{l}^{(f)}, x_{l}, y_{l}, u_{m} \cdot v_{m}, f\right)=P_{l}^{(f)} \cdot \frac{c^{2}}{(4 \pi f)^{2}\left[\left(x_{l}-u_{m}\right)^{2}+\left(y_{l}-v_{m}\right)^{2}\right]} g
$$

Among them, $c$ is the speed of light and $g$ is the antenna gain. From the power value obtained in step $I, M$ equations can be obtained as follows:

$$
\left\{\begin{array}{l}
T_{1}(f)=\sum_{l=1}^{L} F\left(P_{l}^{(f)}, x_{l}, y_{l}, u_{1} \cdot v_{1}, f\right)=\sum_{l=1}^{L} W\left(d_{n}\right) P_{l}^{(f)} \\
T_{M}(f)=\sum_{l=1}^{L} F\left(P_{l}^{(f)}, x_{l}, y_{l}, u_{M} \cdot v_{M}, f\right)=\sum_{l=1}^{L} W\left(d_{M}\right) P_{l}^{(f)}
\end{array}\right.
$$

Among them, $d_{l m}=\sqrt{\left(x_{l}-u_{m}\right)^{2}+\left(y_{l}-v_{m}\right)^{2}}$ is the distance from the first interference source to the $m$ th monitoring point, which is a known quantity, and $T_{m}(f)$ is the received power value, which is also a known quantity. However, the unknown quantity is the transmission power $P_{l}^{(f)}$ of each interference source itself. The system of equations is expressed in matrix form:

$$
T=\left[\begin{array}{c}
T_{1} \\
L \\
T_{M}
\end{array}\right]=\left[\begin{array}{ccc}
W\left(d_{11}\right) & L & W\left(d_{L 1}\right) \\
& L & \\
W\left(d_{1 M}\right) & L & W\left(d_{L M}\right)
\end{array}\right]\left[\begin{array}{cc}
P_{1}^{(f)} & 1 \\
L \\
P_{1}^{(f)}
\end{array}\right]=W P .
$$

From the nature of the matrix, it can be known that as long as $M \geq \mathrm{L}$ is satisfied, that is, the number of monitoring points is not less than the number of interference sources, the transmit power of each interference source can be solved.

The number of interference sources $L$ is a known quantity, and the position coordinates $(x, y)$ of the interference source and its transmission power P. are unknown quantities. At this time, the above matrix equation is

$$
T=\left[\begin{array}{c}
T_{1} \\
L \\
T_{M}
\end{array}\right]=\left[\begin{array}{ccc}
W\left(d_{11}\right) & L & W\left(d_{L 1}\right) \\
& L & \\
W\left(d_{1 M}\right) & L & W\left(d_{L M}\right)
\end{array}\right]\left[\begin{array}{cc}
P_{1}^{(f, \Delta f)} & 1 \\
L \\
P_{L}^{(f, \Delta f)}
\end{array}\right]=W P .
$$

However, at this time, the interference source location $\left(x_{l}, y_{l}\right)$ is unknown, so the matrix changes to:

$$
T=\left[\begin{array}{c}
T_{1} \\
\cdots \\
T_{M}
\end{array}\right]=\left[\begin{array}{ccc}
Z_{1}\left(x_{1}, y_{1}\right) & \cdots & Z_{1}\left(x_{L}, x_{L}\right) \\
& \cdots & \\
Z_{M}\left(x_{1}, y_{1}\right) & \cdots & Z_{M}\left(x_{L}, x_{L}\right)
\end{array}\right]\left[\begin{array}{cc}
P_{1}^{(f, \Delta f)} & 1 \\
L \\
P_{L}^{(f, \Delta f)}
\end{array}\right]=Z P .
$$

Among them, $Z_{m}\left(x_{l}, x_{l}\right)$ is a function of the position $\left(x_{l}, x_{l}\right)$ of the first interference source and the position $\left(u_{m}, v_{m}\right)$ of the $m$ th monitoring point. In the above matrix formula, the interference source coordinate $\left(x_{l}, x_{l}\right)$ and the transmission power $P$ are unknown. It can be seen from the properties of the matrix that if the matrix can get a unique solution, the condition that needs to be met is $M>\beta L, \beta>3$. That is, if the number of monitoring points is more than the number of interference sources, only one solution can be obtained. Using such conditions and solving the equations, we can get the complete information of all interference sources.

The number of interference sources $L$, location $\left(x_{l}, x_{l}\right)$, and transmit power $P_{l}^{(f, \Delta f)}$ are all unknown. In this case, the calculation method in formula (2) can be used for the following analysis. At this time, $L$ is known. If it is required to solve other quantities, the condition that needs to be satisfied is $M>\beta L$. This shows that if the number of monitoring points placed is $M$, the number of interference sources that can be estimated is $L \geq M / \beta$. Here, it is necessary to set a larger estimated value $L_{\max }$ for the number of interference sources, require $L_{\max }>L$, and place $M>\beta L_{\max }$ monitoring points. The position of $L_{\max }$ interference sources can be located and its transmit power can be estimated. Since the number of interference sources is $L$, there are $L_{\max }-L$ 


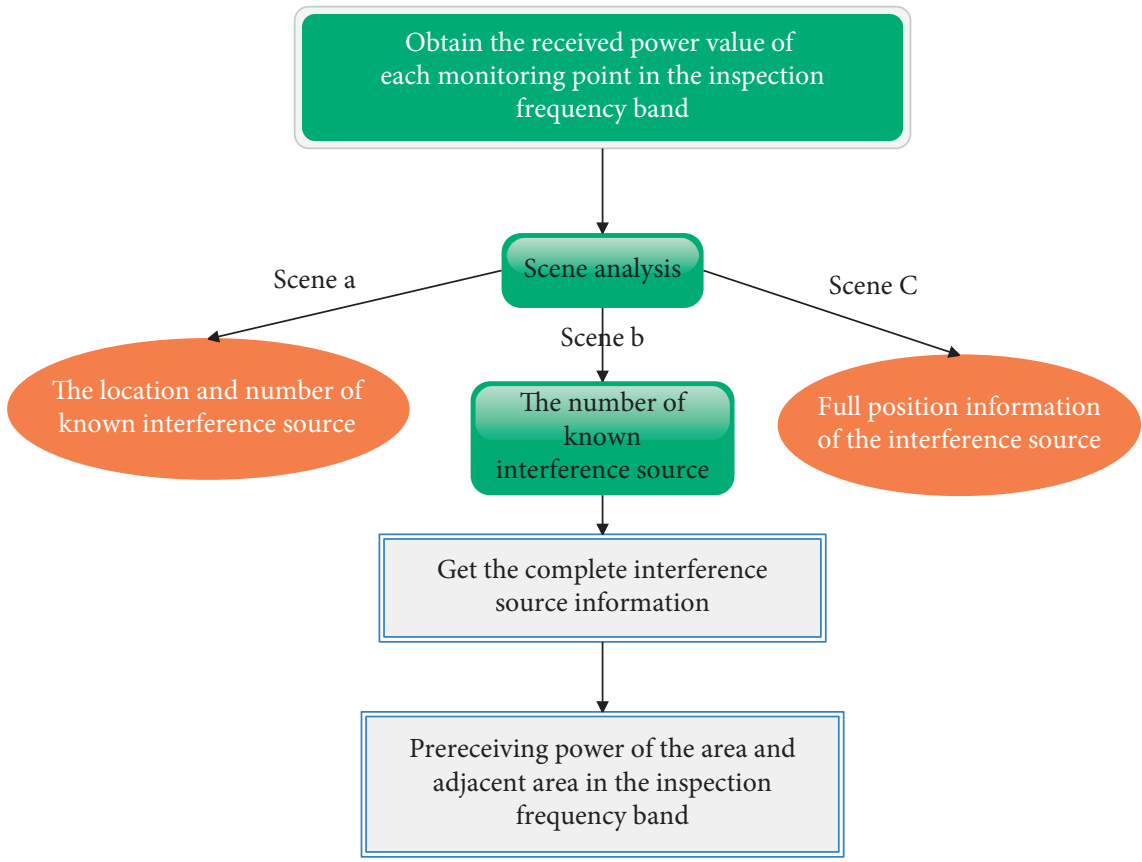

FIgURE 5: Flow chart of spectrum information calculation.

virtual interference sources, that is, the transmit power is 0 and the coordinates are arbitrary. Therefore, we can use this calculation method to remove the interference source with a transmission power of 0 , and the rest is true, and the complete information of the interference source can be obtained.

Therefore, based on the above analysis of different scenarios, we can get complete interference source information.

According to the complete interference source information in the area calculated above, the received power value $T(x, y, f)$ at any point $(x, y)$ in the area can be obtained by calculating the following formula. The calculation formula is as follows:

$$
T(x, y, f)=\sum_{l=1}^{L} F\left(P_{l}^{(f)}, x_{l}, y_{l}, u_{m} \cdot v_{m}, f\right) .
$$

Among them, $F\left(P_{l}^{(f)}, x_{l}, y_{l}, u_{m} . v_{m}, f\right)$ is the received power calculated at the point $(x, y)$ by the Ith interference source. And if you choose a different model, the calculation method of the formula is different. On the other hand, the model must be the same as the signal model selected for the above calculation. Therefore, here, the free space propagation model is also selected, namely,

$$
F\left(P_{l}^{(f)}, x_{l}, y_{l}, u_{m} \cdot v_{m}, f\right)=P_{l}^{(f)} \cdot \frac{c^{2}}{(4 \pi f)^{2}\left[\left(x_{l}-x\right)^{2}+\left(y_{l}-y\right)^{2}\right]} g .
$$

Among them, $c$ is the speed of light and gis the gain.

In summary, the received power value at any point in the investigation area can be calculated through the above steps, so as to complete the calculation of the spectrum information of the area. Through these algorithms, the project cost field verification data processing is completed. The database system of this paper can perform field verification of the project cost in any environment, regardless of the onsite environment.

\section{On-Site Verification System of Engineering Cost Based on Data Mining}

To build a cost information platform, it is necessary to make full use of computer information technology and establish a cost management system based on local area networks and networks. The cost information platform is a cost management database, which transforms the cost information transmitted vertically to horizontal to ensure effective communication and exchange of cost information. If there is a cost management problem during the construction process, we can communicate with all parties through the sharing of cost information, so that the problem can be solved quickly, which reduces or does not increase the cost of the construction project. Figure 6 shows the structure of the information platform.

The basic idea of the application of the earned value method is based on the construction project, through the analysis of the cost and schedule of the project to achieve the target earned value, as shown in Figure 7 . The key point is to 


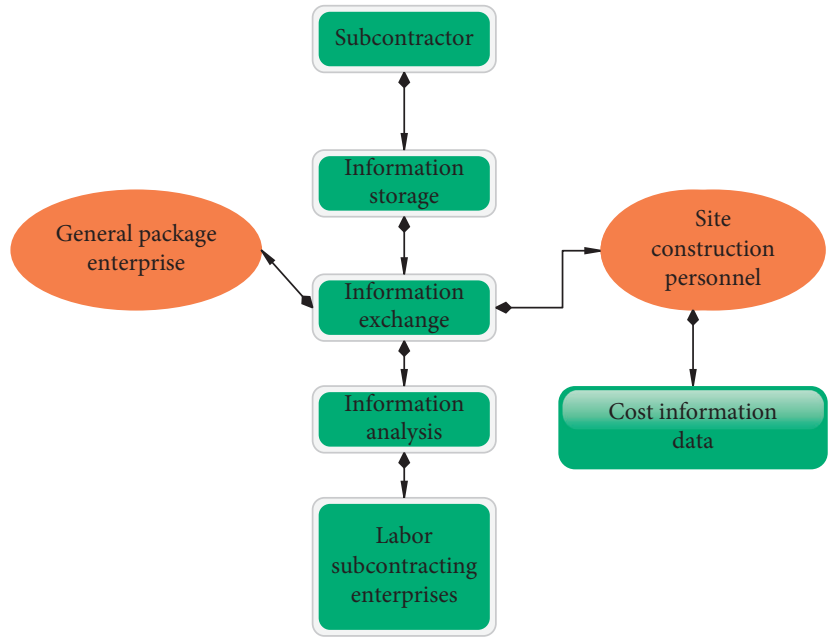

Figure 6: The structure of the information platform.

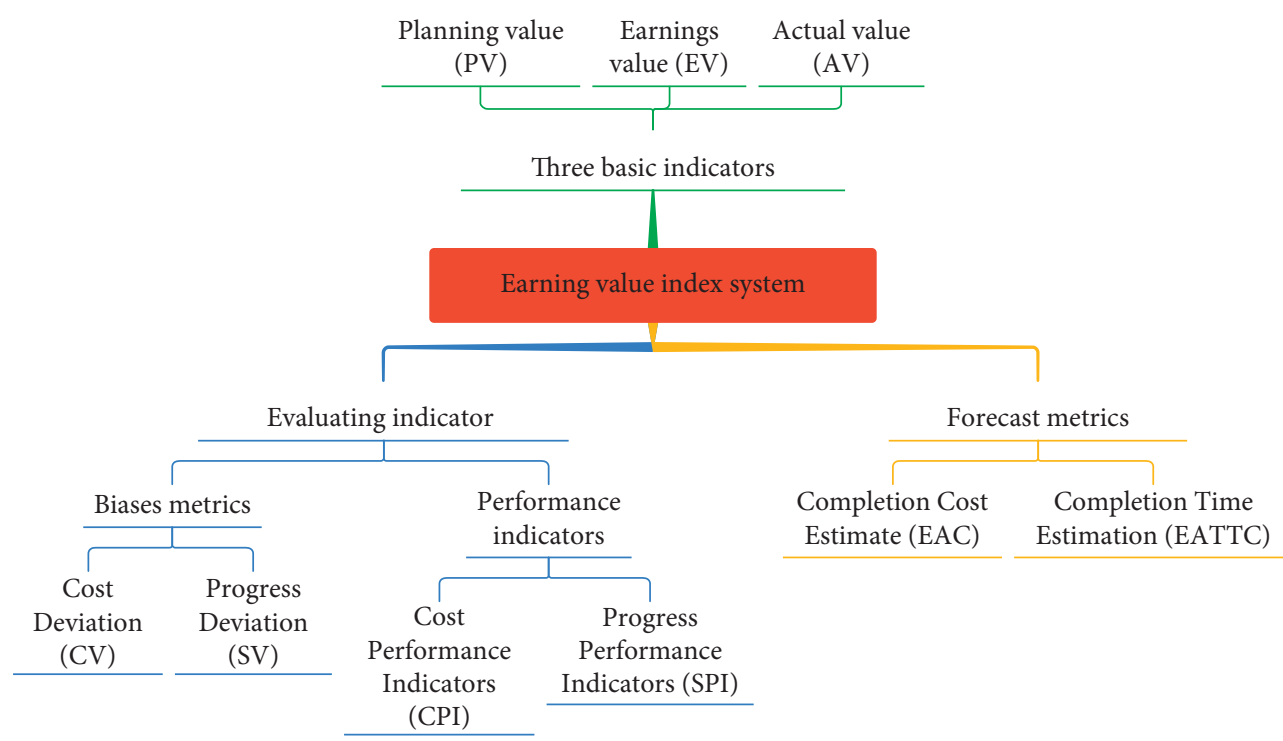

FIGURE 7: The main parameters of the earned value method.

check the cost and schedule regularly, determine whether the cost is overspend and whether the schedule is delayed based on the actual schedule, and then adjust the follow-up work plan of the project and implement feedback before continuing to adjust the plan. However, in the entire analysis process, the actual cost of consumption cannot determine whether a project is overspend because the actual increase in the cost may be caused by the acceleration of the schedule.

The construction project supply chain in this paper refers to a structural chain that controls information, logistics, and capital flow during the entire life cycle of the project. All parties involved in the construction of the project are connected through the general contractor to form a structural chain, as shown in Figure 8.

The organization structure of the construction project is shown in Figure 9.

After constructing the above model, we will explore the role of data mining technology in the on-site verification of

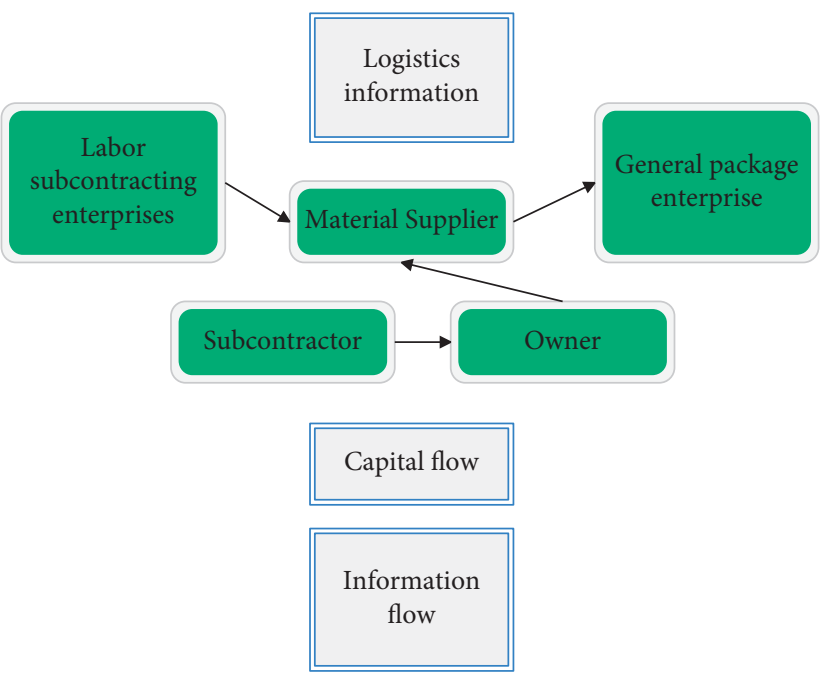

Figure 8: Construction of project management chain. 


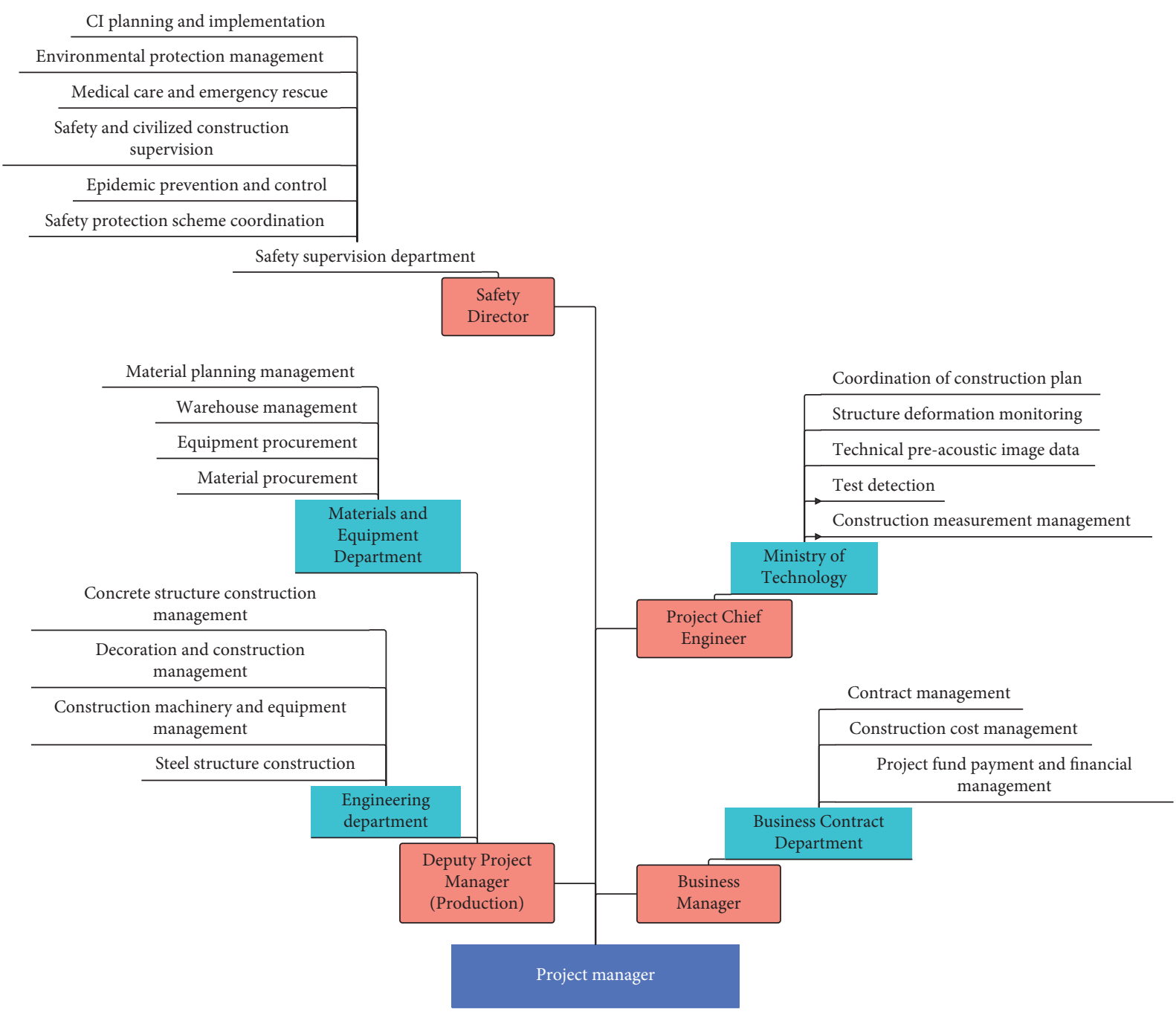

Figure 9: Organizational structure of construction project.

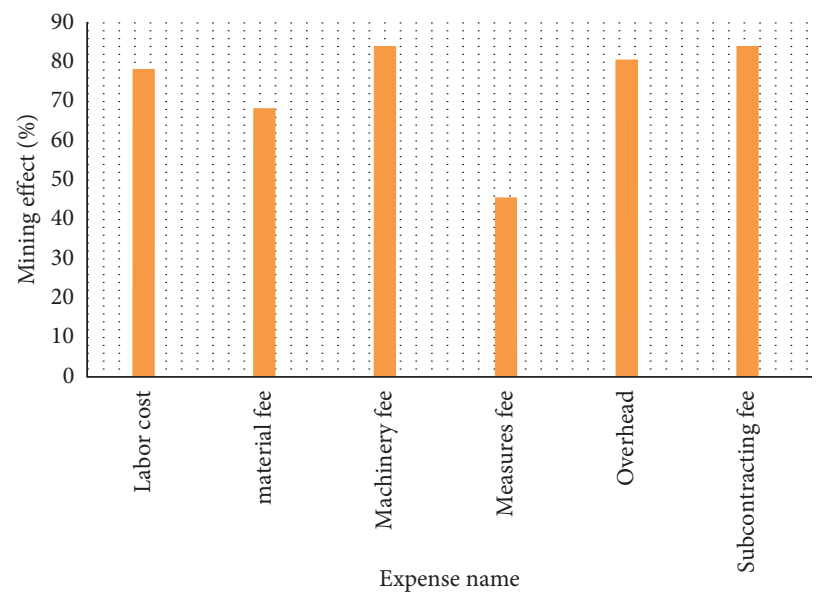

- Mining effect

FIgURE 10: Statistical diagram of the effect of project cost mining.

project cost and first explore the effect of this model in the cost mining of various parts of the project. The statistical results are as follows in Table 1 and Figure 10:
To obtain project information from the Internet, this paper counts multiple sets of project information as test samples and conducts data mining through the model of this paper to obtain 
Table 1: Data mining effect of total project cost.

\begin{tabular}{lcc}
\hline Number & Expense name & Mining effect (\%) \\
\hline 1 & Labor cost & 78.25 \\
2 & Material fee & 68.54 \\
3 & Machinery fee & 84.21 \\
4 & Measures fee & 45.84 \\
5 & Overhead & 81.02 \\
6 & Subcontracting fee & 84.35 \\
\hline
\end{tabular}

TABle 2: Summary of the completion of the plan.

\begin{tabular}{lccc}
\hline Number & Plan & Actual & PPC (\%) \\
\hline 1 & 846 & 928 & 91.14 \\
2 & 734 & 764 & 96.07 \\
3 & 860 & 928 & 92.65 \\
4 & 384 & 450 & 85.37 \\
5 & 349 & 464 & 75.20 \\
6 & 328 & 357 & 91.87 \\
7 & 342 & 307 & 111.39 \\
8 & 314 & 364 & 86.23 \\
9 & 405 & 486 & 83.41 \\
10 & 461 & 585 & 78.74 \\
11 & 540 & 518 & 104.21 \\
12 & 520 & 563 & 92.35 \\
\hline
\end{tabular}

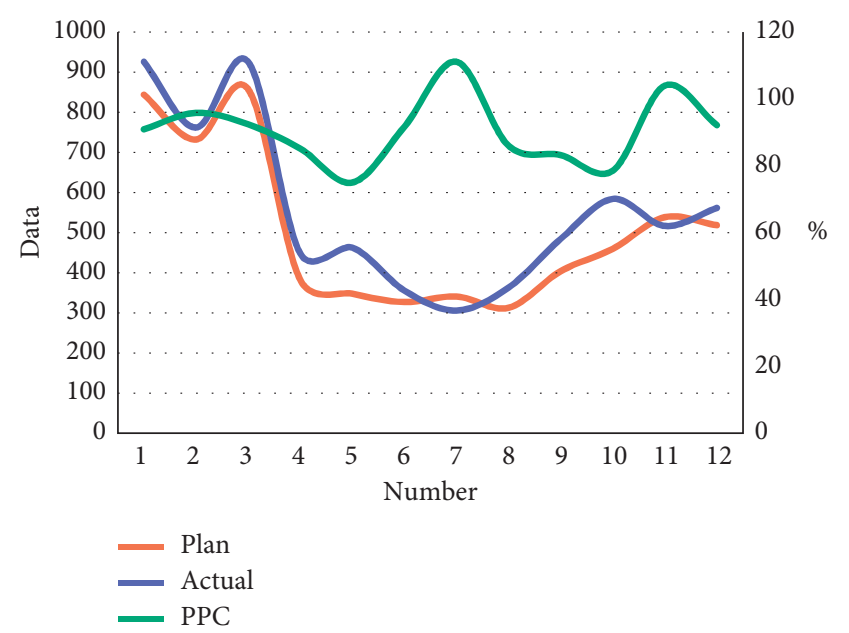

Figure 11: Statistical diagram of the completion of the plan.

a summary table of the completion of the work plan for each week of the construction process and the calculation of the completion rate as shown in Table 2 and Figure 11.

From the above research, we can see that the project cost field verification method based on data mining proposed in this paper is very effective, and the system of this paper can be used in actual projects.

\section{Conclusion}

With the rapid development of economic construction, industrialization, and urbanization, the construction industry has become more prominent in the development of the national economy. As a pillar industry of the national economy, it is closely related to the development of the national economy and the improvement of people's lives. Moreover, project cost control is a complex system engineering as well as a complex process control. It is from bidding decision making to bid winning, from preconstruction plan preparation to construction execution to final completion acceptance. The whole process involves a wide range, many links, and complex participants. Without a reasonable and scientific organizational structure, advanced management, and effective control, it is difficult for an enterprise to succeed. The reasonable prediction of project cost plays a very important role in the control of project cost. The traditional budget quota pricing model seems incompatible with the continuous development of the market economy. Low degree of visualization, extensive resource management, difficulty in collecting construction data, lagging control work, and separation of cost control from project management have become the main problems of current construction project cost control. Based on the actual needs of project cost verification, this paper constructs a project cost verification system that can be used for onsite verification and changes the shortcomings of traditional project cost verification.

\section{Data Availability}

Data sharing is not applicable to this article as no datasets were generated or analyzed during the current study.

\section{Conflicts of Interest}

The author declares no conflicts of interest.

\section{Acknowledgments}

This work was supported by Henan Finance University. 


\section{References}

[1] K. Ataka, "Prediction of election result and economic indicator," Resuscitation, vol. 96, no. 6, p. 84, 2014.

[2] S. Barde, "Back to the future: economic self-organisation and maximum entropy prediction," Computational Economics, vol. 45, no. 2, pp. 337-358, 2015.

[3] A. Ferramosca, D. Limon, and E. F. Camacho, "Economic MPC for a changing economic criterion for linear systems," IEEE Transactions on Automatic Control, vol. 59, no. 10, pp. 2657-2667, 2014.

[4] L. Zhou, K. K. Lai, and J. Yen, "Bankruptcy prediction using SVM models with a new approach to combine features selection and parameter optimisation," International Journal of Systems Science, vol. 45, no. 1-3, pp. 241-253, 2014.

[5] D. Bhattacharya, J. Mukhoti, and A. Konar, "Learning regularity in an economic time-series for structure prediction," Applied Soft Computing, vol. 76, no. 2, pp. 31-44, 2019.

[6] Y. Geng, Z. Wei, H. Zhang, and M. Maimaituerxun, "Analysis and prediction of the coupling coordination relationship between tourism and air environment: yangtze river economic zone in China as example," Discrete Dynamics in Nature and Society, vol. 2020, no. 10, pp. 1-15, 2020.

[7] H. L. Vu, K. T. W. Ng, and D. Bolingbroke, "Time-lagged effects of weekly climatic and socio-economic factors on ANN municipal yard waste prediction models," Waste Management, vol. 84, no. 2, pp. 129-140, 2019.

[8] C. Teljeur, M. O"Neill, P. Moran et al., "Using prediction intervals from random-effects meta-analyses in an economic model," International Journal of Technology Assessment in Health Care, vol. 30, no. 01, pp. 44-49, 2014.

[9] P. Rajsic, A. Weersink, A. Navabi, and K. P. Pauls, "Economics of genomic selection: the role of prediction accuracy and relative genotyping costs," Euphytica, vol. 210, no. 2, pp. 1-18, 2016.

[10] F. Jahedpari, T. Rahwan, S. Hashemi et al., "Online prediction via continuous artificial prediction markets," IEEE Intelligent Systems, vol. 32, no. 1, pp. 61-68, 2017.

[11] V. Daksiya, H. T. Su, Y. H. Chang, and E. Y. M. Lo, "Incorporating socio-economic effects and uncertain rainfall in flood mitigation decision using MCDA," Natural Hazards, vol. 87, no. 1, pp. 515-531, 2017.

[12] S. Lahmiri, "A variational mode decompoisition approach for analysis and forecasting of economic and financial time series," Expert Systems with Applications, vol. 55, no. 8, pp. 268-273, 2016.

[13] N. Gordini, "A genetic algorithm approach for SMEs bankruptcy prediction: empirical evidence from Italy," Expert Systems with Applications, vol. 41, no. 14, pp. 6433-6445, 2014.

[14] A. Ferramosca, A. H. González, D. Limon, and D. Limon, "Offset-free multi-model economic model predictive control for changing economic criterion," Journal of Process Control, vol. 54, no. 3, pp. 1-13, 2017.

[15] C. J. . A. Jane, "Hybrid model combined grey prediction and autoregressive integrated moving average model for talent prediction," Journal of Grey System, vol. 21, no. 2, pp. 91-102, 2018.

[16] A. Khadjeh Nassirtoussi, S. Aghabozorgi, T. Ying Wah, and D. C. L. Ngo, "Text mining for market prediction: a systematic review," Expert Systems with Applications, vol. 41, no. 16, pp. 7653-7670, 2014.

[17] M. Ellis and P. D. Christofides, "Integrating dynamic economic optimization and model predictive control for optimal operation of nonlinear process systems," Control Engineering Practice, vol. 22, no. 1, pp. 242-251, 2014.

[18] W. Schultz, W. R. Stauffer, and A. Lak, "The phasic dopamine signal maturing: from reward via behavioural activation to formal economic utility," Current Opinion in Neurobiology, vol. 43, no. 5, pp. 139-148, 2017.

[19] Q. You, R. Pang, L. Cao, and J. Luo, "Image-based appraisal of real estate properties," IEEE Transactions on Multimedia, vol. 19, no. 12, pp. 2751-2759, 2017.

[20] E. Hromada, "Mapping of real estate prices using data mining techniques," Procedia Engineering, vol. 123, pp. 233-240, 2015. 